\title{
İk Tunç Çağı'nın Son Evresinde Anadolu'nun Siyasal Görünümü
}

\author{
Turgut Yiğit*
}

Özet:

Anadolu'nun henüz tarihsel çağlara girmemiş olduğu İlk Tunç Cağı'nın son evresindeki genel siyasal görünümünü ortaya koyabilmek için öncelikle arkeolojik kazıların sonuçlarını göz önünde bulundurmak gerekir. Farklı coğrafi ortamlara ve büyük ölçüde buna bağlı olarak farklı tarihsel gelişim çizgilerine sahip Anadolu'nun söz konusu çă̆ına ilişkin olarak, bazı Mezopotamyalı kralları konu alan yazılı belgelerden edinilen bilgilerin, yapılan kazıların sonuçlarıyla birlikte değerlendirilmesi ile, doğal ve siyasal zorunluluklarla sinırlanmış bölgelerde çevresindeki daha küçük yerleşmeleri kontrol eden bir kentin merkez olduğu beyliklerin bulunduğu genel siyasal görünümden söz edilebilir.

\section{Abstract:}

The Early Bronze Age settlements in Anatolia have to take consideration mostly according to the results of excavations partially been excavated. However, it is possible to assess in general terms the political situation of Anatolia in this period. The Early Bronze III period in Anatolia is characterized by a culture of largely local development. Central, eastern and south-eastern Anatolia were densely settled areas in the Early Bronze Age III. Fortified towns with small scale urban architecture continued to emerge in traditional centres of economic and political power located in densely populated areas of Anatolia, except in the Black Sea region. Considering that some Early Bronze III settlements produced architectural remains which could only be interpreted as palace coplexes one is tempted to agree with the assesment that city-states dominating the political and economic life in the Anatolia. This also confirmed by writing sources attributed the Akkadian kings.

Anadolu'da M.Ö. 3. binyılda yaşanmış olan ve üç aşamada ele alınan, tuncun gittikçe yaygınlaşan kullanımıyla belirlenen İlk Tunç Çağı; madenin insan yaşamında daha çok yer almasıyla da ilişkilendirilebilecek kültürel, siyasal ve sosyal alanda gelişmelerin ve değişmelerin hız kazandığı dönemdir. Bu çağın son aşamasına kadar olan bilgilerimiz sadece arkeolojik araştırmalar ve kazıların sonuçlarına dayanıyor iken, yine başlica kaynağımız bunlar olmakla birlikte İlk Tunç Çağı III (M.Ö. 2300-2000) olarak adlandırılan son evrede, Mezopotamya'da gelişmiş bir uygarlığa ilişkin yazılı belgelerdeki çok sınırlı da olsa Anadolu'ya dair kayıtlara rastlanmaktadır. M.Ö. 24. yüzyılın ortalarında Agade kenti merkez olmak üzere kral Sargon önderliğinde, Önasya'da çok geniş bir alana yayllacak olan bir imparatorluk kuran Akkadlar, bu dönemde çivi yazısını kullanıyorlardı. Anadolu' ya dek uzanan Akkadlı kralların yazılı belgelerinde ve onlardan çok daha sonra onlara atfen yazıya geçirilmiş efsanevi içerikli 
belgelerde Anadolu'dan, buradaki kentlerden, krallardan bahisler vardir. Anadolu'nun bu dönemdeki siyasal görünümü, şimdiye dek genellikle bazı arkeolojik kazıların sonuçlarına dayalı ve onunla sınırlı olarak ayrı ayrı veya sözünü ettiğimiz yazılı belgelerden birindeki bir iki cümleyle ilgili olmak üzere yorumlanmıştır. Burada, Anadolu'nun protohistorik çağları olarak da söyleyebileceğimiz İlk Tuç Çağı'nın son aşamasına ilişkin söz konusu yazılı belgelerden edinilen bilgiler ve yukarıda değindiğimiz, daha önce bu yönde yorumlara da dayanak olan arkeolojik çalışmaların sonuçlarını birlikte değerlendirmek suretiyle, verilerin sınırlı oluşu da göz önü̉ne alındığında belki farklı sonuçlara ulaşılamamakla birlikte, ancak daha genel bir çerçevede, kaynakların belirlediği farklı iki bakış açısından Anadolu'nun söz konusu dönemdeki siyasal görünümü üzerinde duracă̆ız.

Coğrafi yapısından kaynaklanan doğal sınırları içinde, farklı bölgelerde farklı gelişim çizgileri izlenebilen Anadolu kültürlerinin, İlk Tunç Çağı'nın son evresinde de bu yönü göz önünde tutularak; kazılar sonucunda gün 1şı̆̆ına çıkarılan, politik yapıya ilişkin yorumlara olanak tanıyan buluntular, yine aynı açıdan fikir verebilen yerleşmelerin konumları, boyutları açısından, tüm arkeolojik veriler dikkate alınarak; genel olarak kazı raporlarında ve bunlara dayalı incelemelerde ileri sürülenlerin de değerlendirilerek Anadolu'nun siyasal görünümünün üzerinde durulması, bu konunun özelliği açısından uyulması gereken bir yaklaşım tarzı olarak belirmektedir. Orta Anadolu'nun kazılarla ortaya konulan İlk Tunç III döneminin temsil edildiği merkezlerinin, batı, kuzey ve güneydeki yerleşim yerlerindeki aynı döneme ait tabakalara bakarak konumuz açısından daha dikkati çeken niteliklere sahip olduğu görülmektedir. Anadolu'nun doğusunda ve güneydoğusunda ise aşağıda değineceğimiz üzere, siyasal görünüme dair yorumlara en çok katkıda bulunan kazıların yapıldığı yerleșim yerleri bulunmaktadır.

İlk Tunç Çağı'nda yoğun olarak yerleşilmiş olduğu araştırmaların sonuçlarıyla ortaya konulan Orta Anadolu'nun önemli merkezleri arasında Alacahöyük, Alişar, Kültepe, Acemhöyük, Karaoğlan, Ahlatlıbel, Koçumbeli ve Etiyokuşu sayılabilir.

Çorum'un Alaca ilçesi yakınlarındaki Alacahöyük'te İlk Tunç Çağı'na ait olmak üzere çok önemli buluntular veren on üç mezar, ortaya çıkarılmıştır. Birden fazla kullanılmış olduğu yapılan araştırmalarla anlassılan bu mezarlara bırakılmış olan eşyalar dolayısıyla buralara kimlerin gömülmüş olabileceği yolunda yorumlar yapılabilmektedir. Alacahöyük'ün 3. kültür katına ait olan bu mezarlardan çıkan zengin buluntular, gömünün İlk Tunç Çağı'nın son evresinde, yani Illk Tunç III döneminde yapıldığına işaret êtmektedir'. Bu zengin buluntular, o dönem Anadolu'sunun dini ve sosyal yaşamı hakkında fikirler verdiği, o dönem sanatına dair çok kıymetli bilgiler içeren malzeme olduğu gibi, siyasal yapıya ilişkin ipuçları da sunmaktadır. Álacahöyük'ün güçlü ve zengin bir küçük krallığın ya da beyliğin merkezi olduğu ve söz konusu mezarların da yerel otoriteyi elinde bulunduranlara ve onların dahil olduğu aile mensuplarına ait oldukları kabul edilmektedir ${ }^{2}$. İk

1 H.Z.Kosay-M.Akok, Alacahöyïk Kazısı, 1963-67 Calışmalar ve Keşiflere Ait Ilk Rapor, Ankara 1973, s. XI; U.B. Alkım, Anatolia I, Geneva 1968, s.124

S.Lloyd, Early Highland Peoples of Anatolia, London 1967, s.20 
Tunç III döneminde Alacahöyük'te hüküm süren bir sülalenin üyeleri olarak kabul edebileceğimiz bu mezarlara gömülenlerin kimliklerini, elbette henüz yazı kullanılmadığından bilemiyoruz.

Kalkolitik devirden başlayarak iskan edilmiş ve bulunduğu bölgenin önemli yerleşmelerinden biri olduğu ortaya konulmus olan, Yozgat'in Sorgun ilçesi yakınlarındaki Alişar'ın 3. tabakasının İlk Tunç Çağı'nın son evresine ait olduğu belirlenmiştir ${ }^{3}$. Etrafında kerpiç duvarlı bir surun bulunuyor olmasi, , bu yerleşme yerinin konumuz açısından dikkat çekici yönlerinden birini oluşturmaktadır. Alişar'ın da İlk Tunç III döneminde, tıpkı Alacahöyük'te olduğu gibi, bölgesinde bir merkez konumunda, belli bir gücü elinde bulunduran bir yerleşim yeri olduğu ileri sürülebilir.

Anadolu'nun tarihsel devirlere girdiği M.Ö. 2. binyılın başlarında çok önemli bir merkez olarak karşımıza çıkan Kültepe'nin 13-11. tabakalarının İlk Tunç III dönemini içerdiği belirtilmektedir'.llk Tunç Çağı'nın bu son evresinde de büyük yapıların varlığı,kent etrafındaki tahkimat ve diğer buluntuları, burasının çok iyi bilinen M.Ö. 2. binyılın başlarındaki tarihinden önce de önemli bir merkez olduğu yolunda fikir vermektedir. Belki de Kültepe, daha bu çağda sonraki dönemdeki belirgin rolü olan ticaretle ilgili olmak üzere diğer birkaç Anadolu kentiyle birlikte önem kazanmaya başlamı̧̧ıิ ${ }^{6}$. Nitekim, aşağıda da değineceğimiz üzere, M.Ö. 2350'lerden sonra Önasya tarih sahnesinde önemli bir rol üstlenen Akkad Krallığı'nın kurucusu Sargon'la ilgili yazılı bir belge vasitasıyla, Anadolu ve Mezopotamya arasında daha bu dönemde ticaretin organize bir şekilde yürütülmeye başlandığı yolunda yorumlara dayanak olabilecek bilgiler ediniriz. Kültepe'nin de Ilk Tunç III döneminde idare merkezi, bir yerel sülalenin oturma yeri olabileceği ${ }^{\dagger}$ arkeolojik kazıların sonuçları ve kentin tarihsel önemi göz önünde bulundurularak söylenebilmektedir.

Orta Anadolu'da İlk Tunç III döneminde değinilmesi gereken merkezler arasında Ankara civarında bazı höyükler ve düz yerleşim yerleri de vardır. Ankara'nın güneyindeki Karaoğlan'da İlk Tunç III dönemi 5. tabakada yaşanmıştır. Ưç evreli olan 5. tabakasında sur kalıntılarına rastlanmayan ve bu yönüyle Anadolu'daki diğer önemli İlk Tunç yerleşmelerinden ayrılan Karaoğlan'da, bu çağa ilişkin yerleşmelerin dikkkat çekici olduğu hafiri tarafından da vurgulanmaktadır. Mimariye ait ve diğer kalıntılar dolayısıyla, gelişmiş, iş bölümünü, sosyal hiyerarşiyi ve mülkiyeti tanıyan bir toplulugun varlığının Karaoğlan için kabul edilebileceği belirtilmektedir ${ }^{8}$. Yine Ankara'nın güneybatısındaki Ahlatlıbel'de yapılan kazılarda İlk Tunç III

${ }^{3}$ Alkım, a.g.e, s.123; J.Yakar,The Later Prehistory of Anatolia,The Late Chalcolithic and Early Bronze Age I, 1985, s.198.

4 J.Mellaart, "Anatolia, c.2300-1750," CAH I/2, Cambridge 1971, s.688.

5 J.Yakar, "Regional and Local Schools of Metalwork in Early Bronze Age Anatolia," An.St. 35(1985), s.34; Yakar, The Later Prehistory. I, s.199.

6 J.Mellaart, The Chalcolithic and Early Bronze Ages in the Near East and Anatolia, Beirut, 1966, s.179,190; M.Mellink, "The Early Bronze Age in West Anatolia," The End of the Early Bronze Age in the Aegean (ed. Gerald Cadogan), Leiden 1986, s.139.

${ }^{7}$ Yakar, An.St. 35, s.34

s R.O.Arık, "Karaoğlan Höyüğü Bakır Çağı Mimarlığğındaki Özellikler," III.Türk Tarih Kongresi 1943, Ankara 1948, s.48-49, 58-59. 
yerleşmesinde bir kale ve onu çevreleyen sur kalıntılarına rastlanmıştır' Ortaya çıkarılan yapılar, büyüklüğü ve ele geçen diğer buluntular, buraşının sıradan bir müstahkem mevki olamayacağını, önemli bir kişinin, belki bir yerel kralın kalabalık maiyetiyle birlikte yaşadı ğı yer olabileceğini göstermektedir ${ }^{10}$. Ankara yakınlarındaki bir başka yerleşim yeri olan Koçumbeli de Ahlatlıbel ile benzer özelliklere sahip ${ }^{11}$, yani bölgesinde otorite sahibi yerel bir sülalenin oturma yeri olarak kabul edilmektedir ${ }^{12}$. Ilk Tunç Çağı'nın son evresinin temsil edilmiş olduğu Ankara yakınlarındaki Etiyokuşu'nda yapılan kazılarda etrafı bir sur ile çevrilmiş olan bu yerleşmenin zaman içinde gelişim gösterdiği anlaşılmıştır ${ }^{13}$.

Yine Orta Anadolu'daki merkezlerden ikisi, Aksaray yakınlarındaki Yeşilova'da bulunan ve İlk Tunç Çă̆g'nın son evresinin 8. tabakasında yaşandığ 1 belirlenen ${ }^{14}$ Acemhöyük ile, bu evrenin 5-6. tabakalarda temsil edildiği ortaya konulmuş olan ${ }^{15}$ Konya yakınlarındaki Karahöyük'ün, buralarda yapılan kazılarda ele geçen buluntularla ve höyüklerin boyutları dolayısıyla, söz konusu çă̆ın önemli yerleşmeleri oldukları anlaşılabilmektedir ${ }^{16}$.

Anadolu'nun güneyinde de İlk Tunç Çă̆ı'nda iskkan edilmiş yerlerin bulunduğu görülmektedir. Çukurova'daki, önceleri Kuzey Mezopotamya ve Suriye ile olan ilişkinin azalarak, bu dönemde Anadolu etkisinin daha çok görülmeye başlandığı gözlemlenmektedir ${ }^{17}$. Güneydeki kazılar sonucunda, Ilk Tunç Çağı'nın son aşamásı Tarsus Gözlükule'de dört evreli olarak tanınabilmiştir ${ }^{8}$. İlk evre küçük mimari kalıntılar sunarken, ikinci evrede megaron planlı yapılar görülmeye başlanmaktadır. Üçüncü evre ile artık burada büyük bir kentten bahsetmek mümkün olmaktadır. Tahkim edilmiş olän bu yerlesim yerinin de yerel bir krallığın merkezi olabileceği ileri sürülmektedir ${ }^{19}$.

Etrafının surla çevrilmiş olduğu araştırmalar sonucunda saptanmış olan ve 6-12. tabakaları İlk Tunç III'e tarihlenen ${ }^{20}$ Denizli'nin Çivril ilçesi yakınlarındaki Beycesultan, Anadolu'nun güneybatısındaki, bölgeşinin merkezi konumunda olabilecek bir yerleşim yeri olarak dikkati çekmektedir.

\footnotetext{
${ }^{9}$ Hamit Zübeyr, "Ahlatlıbel Hafriyatı," Türk Tarih, Arkeologya ve Etnografja Dergisi 2(1934), s.6.

11 Hamit Zübeyr, a.g.e., s.8,12; Alkım, a.g.e, s.121; J.Yakar, The Later Prehistory. I, 1985 , s.39,66; Yakar, An.St.35, s.33.

${ }_{11}$ B.Tezcan, 1964 Koçumbeli Kazısı, Ankara 1966, s.11.

12 Alkım, a.g.e, s.122; Yakar,The Later Prehistory. I, s.39,66

13 Ş.A.Kansu, Türk Tarih Kurumu Taraftndan Yapilan Etiyokuşu Hafriyatl Raporu (1937), Ánkara 1940, s.19-20

14 Yakar, The Later Prehistory. I, s.199-200. 37, s. 435

15 S.Alp, "Karahöyük Kazısı," Belleten 3l, s.457; S.Alp, "Karahöyük Kazısı," Belleten

16 İlerdeki sayfalarda değineceğimiz üzere,_ar tamhari metinlerinde yerel bir kral tarafından idare ediliyor olarak görülen Puru_handa'nın büyük olastlıkla Acemhöyük olabileceği kabul edilir

${ }_{17}$ Vevin, Anadolu Arkeolojisi, İ stanbul 1997, s.89

${ }_{19}^{18}$ H.Goldmann, Excavations at Gözlii Kule, Tarsus II, New Jersey 1956, s.32 vd.

19 Alkım, e.g.e., s.83

30 S.Lloyd-J.Mellart, Beycesultan I, London 1962, s.58 vd.
} 
Troia, Çanakkale Boğazı'nın Ege girişindeki Hisarlıktepe'de bulunan ve Batı Anadolu'da İlk Tunç Çağı tabakalarıyla ilgili olmak üzere şüphesiz en çok göze çarpan merkezdir. Burada $2 \mathrm{c}$-g evreleri İlk Tunç III dönemine tarihlenmektedir ${ }^{2}$. Troia'nın 2. tabakasının bir sur duvarından ve bunun yanı sıra saray olabileceği belirtilen büyük yapı kompleksleri bulunduğundan bahsedilmektedir ${ }^{22}$. Meşhur Troia hazinesinin de ait olduğu İk Tunç III dönemi Troia'sı da bir kralın oturduğu kent olarak tanımlanmaktadır ${ }^{23}$. Batı Anadolu'da İlk Tunç Çağı ile ilgili olmak üzere yine böyle yorumlamalara imkan verebilecek bir yerleşim yeri de Urla Limantepe'dir.

Diğer bölgelerine bakarak Anadolu'nun kuzeyi, İlk Tunç Çağı'nda daha az iskan edilmiş olarak görünmektedir. Bu devrin yaşanmış olduğu tespit edilmiş olan yerleşim yerlerinden Bafra'nın kuzeybatısında Kızılırmak kiyısinda bulunan İkiztepe, Samsun'daki Dündartepe ve Samsun'un güneyindeki Kavak'ta yapılan araştırmalarda bu dönemin mimarisinin zayıf olduğu ve bir idari merkezi göstermeyeceği anlaşılmıştır ${ }^{24}$. Ancak, İlk Tunç Căğı III'ten sonraki dönemde Kızılırmak'in Karadeniz'e döküldü̈ğu yerdeki İkiztepe'nin, burada yapılan kazıların sonuçlarına göre, yerel bir otoritenin merkezi olabileceği ileri sürü̈lmüştür ${ }^{25}$. Yine Kuzey Anadolu'nun sınırları dahilinde görebileceğimiz, İlk Tunç Çăğı'nın son aşamasına tarihlenen, Tokat'ın kuzeyindeki Erbaa yakınındaki Horoztepe mezarlığının, Alacahöyük mezarlarından en geç olanlarıyla çağdaş ya da onlardan dahá geç olabileceği, burada ele geçen buluntulara göre tarihlemenin en erken 2100 'lere yapılabileceği kazıları yürüten arkeologlar tarafından belirtilmiştir ${ }^{26}$. Mezar buluntuları Alacahöyük kral mezarlarıyla benzerlik göstermektedir. Amasya'nın Mahmatlar köyünde bulunan, bir mezara ait olup olmadığı kesin olarak anlaşılamayan defineye ait eserler de Alacahöyük eserleriyle benzerlik gösterir ${ }^{27}$. Horoztepe ve Mahmatlar'ın o devirlerde müstahkem kentler olmadığı, ancak bölgelerindeki arazilerin sahibi olan beylerin oturma yerleri olduğu yolunda görüşler öne sürülmüştür ${ }^{28}$.

Yapılan araştırmalarla İlk Tunç Çağı'nın Anadolu'nun doğu ve güneydoğusunda da önemli ölçüde temsil edildiği anlaşılmıştır. Daha çok Suriye ve Mezopotamya kültürleriyle ilişkili olarak karşımıza çıkan ${ }^{29}$ güneydoğunun bu dönemde yoğun olarak iskan edildiği görülmektedir. Islahiye bölgesindeki Tilmenhöyük'te yapılan kazılarda $3 \mathrm{~d}-\mathrm{e}$ safhalarının İlkTunç III dönemine ait oldukları ve bu evrelerde Tilmehöyük'ün önemli bir yerleşmeye sahne olduğu ortaya konulabilmektedir ${ }^{30}$. M.Ö. 3. binyılın son çeyreğinde kalabalık bir yerleşme olan Tilmenhöyük ve yine bu

${ }^{21}$ C.W.Blegen, Troy I,1,1950, s.201 vd.

${ }_{22}^{22}$ Blegen, a.g.e., s.205.

${ }^{23}$ Blegen, a.g.e., s.372; S.Lloyd, "The Earlly Settlement of Anatolia," The Dawn of Civilization, London 1961, s. 187; Yakar, The Later Prehistory. I, s. 39, 66

${ }_{24}$ Yakar, An.St. 35, s.30

${ }^{25}$ U.B.Alkım-H.Alkım-Ö.Bilgi, Ikiztepe I, Ankara 1988, s.58. s.31.

${ }^{26}$ Özgüç-M.Akok, Horoztepe, Eski Tunç Devri Mezarltğı ve Iskan Yeri, Ankara 1958,

${ }_{27}$ H.Koşay-M.Akok, "Amasya Mahmatlar Köyü Definesi," Belleten 14(1950), s. 481,483 .

${ }^{28}$ Özgüç-Akok, a.g.e., s.32.

${ }^{29}$ Sevin, a.g.e., s. 97

31) U.B.Alkım, "Dördüncü Dönem Tilmen Höyük Kazısı (1962)," TAD 12 (1962), s.7;

U.B.Alkım, "İslahiye Bölgesi Araştırmaları ve Tilmen Höyük Kazısı," TAD 13 (1964), s.8. 
bölgedeki Gedikli'nin aynı zamanda bulundukları yerlerin idare merkezi konumunda oldukları ileri sürülmektedir ${ }^{31}$. Güneydoğudaki kentleşmenin örnekleri olarak, bu döneme ait olmak üzere, Kargamış, Zincirli, Samsat ve Lidarhöyük'ün de adları verilebilir ${ }^{32}$. Şanlıurfa yakındaki Titriş ve Kazane, Harran ovasındaki Harran ${ }^{33}$ höyükleri de söz konusu dönemin dikkati çeken yerleşmelerindendir.

İlk Tunç Çă̆ı'nın başlarında Mezopotamya ve Kuzey Suriye kültürlerinin etkisindeyken, bu çağın sonraki aşamalarında olan yoğun göçlerle giderek Erken Transkafkasya kültürünün etkisi altına giren Doğu Anadolu, diğer bölgelerden daha farklı niteliğiyle karşımıza çıkar ${ }^{34}$. Keban baraj gölü altında kalan, 11-13. tabakaları İlk Tunç III dönemine tarihlenen Tepecik ${ }^{35}$, bu çağda bir kent yerleşmesinden çok bủyük bir köy veya kasaba olarak tanımlanmaktadır ${ }^{36}$. Yine aynı bölgedeki Korucutepe'nin E evresi İlk Tunç III'ün erken, $F$ evresi da geç dönemlerine konulmaktadır ${ }^{37}$. Korucutepe'nin bu bölgenin önemli yerleşmelerinden biri, hatta belki bulunduğu yerin idare merkezi olduğu yolunda görüşler ileri sürülmüş̧tür ${ }^{38}$. Tıpkı Korucutepe gibi, bölgenin önemli bir yerleşmesi olan Norşuntepe' de 6 . tabaka İlk Tunç III'e verilirken, 7. ve 8. tabakalar İlk Tunç III'ün erken evrelerine aittirler ${ }^{39}$. 6. tabakaya ait olmak üzere, bir beyin oturmuş olabileceği şeklinde kullanımına ilişkin yorumlar yapılabilen ana bölüm niteliğinde kısmı bulunan anıtsal bir yapının kalıntıları ortaya çıkarılmıştır ${ }^{40}$. İlk Tunç Çă̆ı'nın son evresinde Norşuntepe'de 6. tabakada (ca. 2200) gelişmiş binalar varken, bu yerleşim yerinin dışındaki daha mütevazı binaların bulunduğu yerlerin gittikçe önemini kaybettiği ve herhalde burasının diğerlerinin bağlı olduğu bir merkez konumuna geldiği, yani Norşutepe'nin bölgesinin merkezi olduğu yolunda görüş̧ler vardır. Hatta sadece Norşuntepe'nin değil, yukarıda değindiğimiz Korucutepe, Tepecik ve adlarını ilk kez anacağımız aynı bölgedeki Tülintepe ve Könk'ün de bölgelerindeki daha küçük yerleşim yerlerini kontrol eden merkezler olabilecekleri üzerinde durulur. Bu durumun sadece bu yöreye özgü olmayıp, Anadolu'nun diğer kısımlarının çoğu için de İlk Tunç Çağı'nın karakteristik özelliği olduğunu artık biliyoruz ${ }^{41}$. Saydığımız, yapılan araștırmaların ve kazıların sonucundaki bulgulara göre kendi bölgesinde bir

${ }^{31}$ Alkım, Anatolia I, s.94; Yakar, The Later Prehistory. I, s.47.

${ }^{32}$ Yakar, a.g.y.

${ }^{33}$ Harran'ın Illk Tunç Çağı'nın son dönemlerinde bölgenin siyasal görünümüne katkıda bulunan ilgi çekici bir bilgi olarak, bir kraliçenin yönetiminde olduğuna ileride kısaca değinilecektir.

${ }^{34}$ Sevin, a.g.e., s. $93-94$ vd.

35 U.Esin, "Tepecik Kazısı, 1970," Keban Projesi 1970 Çalışmalarl, Ankara1972, s.137

${ }^{36}$ U.Esin, "Tepecik Kazısı, 1974," Keban Projesi 1974-75 Çalş̧malart, Ankara 1982, s.93 dn.59.

${ }^{37}$ M.N.van Loon, Korucutepe II, New York 1978, s.6.

${ }^{38}$ Yakar, The Later Prehistoy. II, s.280.

${ }^{39}$ H.Hauptmann, "Norşuntepe Kazısı,1969," Keban Projesi 1969 Çalışmaları, Ankara 1971, s. 71 vd; H.Hauptmann, "Norşuntepe Kazıları, 1973," Keban Projesi 1973 Çalışmalart, Ankara 1979 , s.43 vd

40 H.Hauptmann, "Norşuntepe Kazıları, 1971," Keban Projesi 197I Çalışmalart, Ankara 1974, s.72 vd.

${ }^{41}$ H.Hauptmann. "Kalkolitik Cağdan Ilk Tunç Çağının Bitimine Kadar Norşuntepe'de Yerleşmenin Gelişimi," VIII.Türk Tarih Kongresi I.cilt, Ankara 1979. s.63. 
odak olabileceği yönünde yorumlar yapılabilen yerleşmelerin dışında, Anadolu'nun doğusunda İlk Tunç III döneminin temsil edildiği bir merkez olan Malatya Arslantepe de benzer özelliklere sahip bir yerleşim yeridir.

Anadolu'nun farklı bölgelerindeki İlk Tunç Çă̆ı'nın son aşamasındaki durumuna, siyasal yapı açısından fikir verebilecek nitelikteki yerleşim yerlerini ele alarak değindikten sonra, bu dönemdeki genel görünüme baktığımızda, orta, güney ve güneydoğuda kentlerin bulunduğu, buralarda yapılan kazılarda gün ışı̆̆ına çıkarılan buluntuların, özellikle mimari kalıntıların, kimi yerleşim yerlerinin bölgesinde egemen olan kent devletleri olduğu yolunda izler sunduğu görülmektedir. Kent devleti olarak Anadolu'daki kimi İlk Tunç III yerleşmelerini tanımlamak, belki sadece arkeolojik verilere bakarak erken söylenmiş olabilir. Ancak özellikle Keban baraj gölü altında kalan Norşuntepe gibi büyük boyutlu ve dikkat çekici mimari kalıntılara sahip olan bir yerleşim yeri için bunu söylemek daha kolaydır. Nitekim, aşağıda ele alacağımız üzere, çok sınırlı sayıdaki yazılı belgelerdeki kayitlarla da yorumlar yapılabilen Anadolu'nun o dönem siyasal yapısına, yine sınırlı sayıdaki kazılarda ulaşılan İk Tunç III dőnemine ait bulguların yorumları paralellik göstermektedir. Norşuntepe'nin yanı sıra yine o bölgenin höyüklerinden Korucutepe, Tepecik, Tülintepe, Gaziantep bölgesindeki Tilmenhöyük'ün bulundukları yerlerin merkezi konumda olabileceklerine, iç kısımlardaki Ahlatlıbel, Koçumbeli, Alacahöyük, Alişar'ın yanı sıra batıda Troia, Limantepe, güneyde Tarsus Gözlükule için de aynı yönde yorumlarda bulunulduğuna yukarıda değinildi. Bunların dışında, her ne kadar doğrudan bu türlü yorumlara konu olmasalar da, Demircihöyük, Kalehöyük, Gelinciktepe, Semsiyetepe, İmamoğlu, Köşkerbaba, Pirot, İmikuşağı, Pulur, Han İbrahim Şah, Değirmentepe, Karagündüz ve Dilkaya da söz konusu dönem Anadolu'suna ilişkin bilgilerimize katkıda bulunan merkezlerdir.

İlk Tunç III dönemi, kentleşmenin hız kazandığı ve Anadolu'da kent devletlerinin varlığının ortaya konulduğu süreç olarak anılabilir. Bunu yukarıda da değindiğimiz üzere, bu döneme ait saray, kamu binaları olarak yorumlanabilen çok odalı büyük boyutlu mimari kalıntıların kazılar sonucunda açığa çıkarılması ve aşağıda değineceğimiz yazılı kaynaklardaki ilgili kayıtlara dayanarak söyleyebiliyoruz. Ilk Tunç III, Anadolu'da belli bir bölgede hakim olan siyasal ve askeri gücü elinde bulunduran sülalelerin ortaya çıkış dönemi olarak belirlenmektedir ${ }^{42}$. Söz konusu döneme ait buluntuların değerlendirilmesi, kentlerin ortaya çıkışı, ortak tarım çalışması, sosyo-politik organizasyonlar, metal işleme sanat, yani profesyonellik gerektiren, toplum ihtiyacına yönelik çalışmalar, iş bölümü, buna bağlı olarak toplumsal tabakalanma ve Anadolu'da bu dönemde çok sayıda kent devletinin olduğuna ${ }^{43}$ dair yorumlara kuvvet kazandırır. Anadolu'nun batısı, bu anlamda orta ve güneydoğusu kadar gelişmemiştir ${ }^{44}$. İlk Tunç Çăgı'nın son evresine tarihlenen yerleşmelerde sur duvarlarının ortaya çıkarılmış olması, sürekli dış tehdidin olduğuna kanıt sayılmaktadır. Anadolu'nun bu dönemdeki siyasal yapısına, yani kent devletleri ve bunların birbirleriyle olan mücadelelerine bağlanabileceği gibi, aynı zamanda bu durum dışarıdan

\footnotetext{
${ }^{42}$ Yakar, a.g.e. I, s. 36, 47; II, s. 280, 399

${ }^{43}$ Alkım, Anatolia I, s.81.

4 Mellink, a.g.e., s. 139.
} 
olan istila hareketleriyle de ilgili görülebilir. Mezopotamyalılar'm yazılı belgeleriyle ve arkeolojik kanitlarla da bildiğimiz bu dönemdeki askeri seferlerinden başka, belki daha önemli olmak üzere buraya olan göçlerden söz edilebilir. Nitekim bu göçlerin, istilaların daha sonra yazılı belgelerden tanıdı ̆̆ımız Luwiler'le ilgili olabileceği yolunda görüşler vardır ${ }^{45}$. Bu bağlamda Hurriler'in de bu dönemde Kilikya'da bulunduklarinın ileri sürülüyor olması hatırlanmalıdır ${ }^{46}$.

İk Tunç Çağı'nın son evresinde Anadolu'nun genel siyasal görünümüne dair arkeolojik kazıların sonuçlarına dayalı olarak ortaya konulabilen düşünceleri, bu dönemde Mezopotamya'da hüküm süren, ancak idare ettikleri devletin etki alanı Mezopotamya sınırlarını aşan Akkadlı krallara ilişkin belgelerdeki kimi kayıtlarla da destekleyebilmekteyiz. M.Ö. 4. binyılın sonlarına doğru Mezopotamya'nın güneyinde ilk kez karşımıza çıan yazı, Akkad devleti (M.Ö. 2350-2150) zamanında bu uygarlığı ortaya koyanlar tarafından da kullanılmaktaydı. Anadolu'nun henüz yazı ile tanışmadığı bu dönem, Akkadlı kralların tarihsel içerikli yazıtlarındaki bu topraklara dair sınırlı kayıtları dolayısıyla Anadolu'nun protohistorik çağı olarak da adlandırılır. Ancak bizim üzerinde duracağımız metinler, doğrudan o dönemden günümüze ulaşmayıp, Akkadlı kralları ve onların yaptıklarını konu alan, efsanevi içerikli ve çok daha sonraki dönemlerden ve farklı uygarlık çevrelerinden günümüze ulaşan ulaşanlardır.

Anadolu'ya ilişkin en eski içerikli bilgilerin bulunduğu _ar tamhari (savaşın kralı) adıyla anılan efsanevi metinlerin, Mezopotamya'da, Mısır'da Tell el Amarna'da ve Anadolu'da Boğazköy arşivinde nüshaları ele geçmiştir ${ }^{47}$. Sarayına dek gelen tüccarların yardım istekleri üzerine olsa gerek, Acemhöyük'te lokalize edilmek istenen Bur_ahanda(Puru_handa)'ya ${ }^{48}$ dek olan, Akkad kralı Sargon'un Anadolu'ya

${ }^{45}$ S.Lloyd, Early Highland. s, 38; J.Mellaart, "The End of the Early Bronze Age in Anatolia and the Aegean," AJA 62 (1958), s.26; Mellart, The Chalcolithic and Early Bronze Ages in the Near East and Anatolia, s.177. Mellaart, AJA 62'de Hititler ve Palalar'1 da bu istila hareketine katar.

${ }_{46}$ Mellaart, $A J A$ 62, s.24; Mellaart, The Chalcolithic., s.171.Hurriler'in üçüncü binyılda Doğu Anadolu'nun yerleşikleri olduğu ileri sürülür: C.A.Burney, "Eastern Anatolia in the Chalcolithic and Early Bronze Age," An.St. 8(1958), s.166; H.Z.Koşay, "Pulur(Sakyol) Kazısı 1969," Keban Projesi 1969 Çalısmalart, Ankara 1971, s.99 vd.

${ }^{47}$ Bu metinlerin Tell el Amarna nüshası VAS XII Nr.193'te çivi yazılı kopyası yayınlanmış, O.Schroeder, "Die beiden neueu Tontafel," MDOG 55 (1914), s.39-45'te tercümesi verilerek işlenmiştir. E.Weidner, Der Zug Sargons von Akkad nach Kleinasien, BoSt VI,1922, s.62-71'de transkripsiyon ve tercümesi ile yayınlanmıştır. Bir tercüme ve inceleme de W.F.Albright, "The Epic of the King of Battle: Sargon of Akkad in Cappadocia," JSOR 7 (1923), s.1-20'de verilmiştir. Asur nüshasının KAV 138'de çivi yazılı kopyası yayınlanmış, Weidner, BoSt $V I$, s.75'te üzerinde durulmuş, transkripsiyonu verilmiştir. Boğazköy nüshası KBo III 9 (BoTU 1), H.G.Güterbock, "Die Tradition und ihre literarische Gestaltung bei Babyloniern und Hethitern bis 1200,Zweiter Teil:Hethiter," ZA 44 (1938), s. 45-46'da transkripsiyon ve tercümesi ,ile yayınlanmıştır. KBo XXII 6, H.G.Güterbock, "Ein neues Bruchstück der Sargon-Erzahlung 'König de Schlacht', MDOG 101(1969), s.14-26'da yayınlanmıştır. Boğazköy' de ele geçenler dışında diğer nüshalar toplu olarak J.G.Westenholz, Legends of the Kings of Akkade, The Texts, Indiana 1997, s. 102-139'da ele alınmıştır.

48 _ar tamhari metinlerinin Tell el Amarna nüshasında Bur_ahanda olarak geçen bu kentin ad̄ Hititce civi yazılı belgelerde, Puru_handa, Par_uhand/ta formunda yer almaktadır: Bak.H.Ertem, Boğazköy Metinlerinde Geçen Coğrafya Ádlar Dizini, Ankara 1973, s.113; G.F.del Monte-J.Tischler, Die Orts-und Gewassemamen der hethitischen Texte (RGTC VI), 
seferini konu alan metinde anlatılanlar, Amarna nüshası temel olmak üzere özet olarak şöyledir: Öncelikle kral Sargon'a, Bur_ahanda'ya değin yolun zorlukları, geçilmez ve zahmetli olduğu anlatılmaktadır (öy. 1-12). Daha sonra tüccarların, huzuruna çıkarak ve savaşçı olmadıklarını belirterek Sargon'dan yardım istemeleri vardır ( $\mathrm{Bu}$ tüccarlar Anadolu'daki Bur_ahanda[Puru_handa] kentinden ve şikayetlerinin konusu da Anadolulu yer $\bar{i}$ bir kral olan Nur-daggal olmalıdır) (öy. 13-20). Sargon'un sorması üzerine tekrar Bur_ahanda'ya değin yolun güçlüklerinden bahsedilir (öy. 2127). Metnin arka yüzünün ilk bölümünde Nur-daggal ve onun hitap ettiği askerlerinin Sargon'a meydan okur tarzdaki ifadeleri yer almaktadır. Hemen arkasından da Sargon'un Nur-daggal'ın kentini ele geçirdiği anlatılır. Sargon'un kuvvetleri, metinden anlaşıldığına göre kentin surlarını yıkmış ve herhalde ciddi bir direnmeyle karşılaşmaksızın ele geçirmiştir (ay. 3-12). Nur-daggal'in Sargon'un huzuruna getirilmesi, Sargon'un Nur-daggal'a çıkışması ve onun Sargon'un üstünlüğünü kabul ettiğini bildiren sözleri... (ay. 13-23).

Tell el Amarna nüshasında Bur_ahanda(Puru_handa) kentinin adı ve Nur-daggal adındaki bir yerel kralı̄n adı geçmesine răgmen, tüccarları sıkıntıya uğratan bu kişinin Puru_handa kralı olup olmadığı açıkça anlaşılamaz. Sargon'un Bur_ahanda'ya değin yolları sorması ve ona bu yolun güçlüklerinin anlatılması ilk olarak Nur-daggal'in kentinin Puru_handa olabileceğini akla getirir. Nitekim, bu metnin Boğazköy arşivinde ele gecen KBo XXII 6 no'lu fragmanın 21. satırındaki "mur-dahhi LUGAL KUR " ${ }^{\text {IRU }}$ Puru_handa" ifadesinin okunmasıyla böyle olduğu açıkça görülmektedir ${ }^{49}$.

Asur Ticaret Kolonileri dönemine ait olmak üzere Kültepe'de gün ışı̆̆ına çıkarılmış olan, Akkad kralı Sargon'un Anadolu'nun içlerine dek sefer yaptığının öğrenildiği bir başka metin, Eski Asur lehçesi ile yazılmış olan bir hikayedir' ${ }^{50}$. Bu metinde Kani 'ten bahsedilmekte, Hattumlular' in (Hatti) cezalandırıldı ğı anlatılmaktadır. Sargon'un Anadolu ile ilgisine ilginç bir kanıt da Hitit kralı I.Hattu_ili'nin Yıllıkları'ndadır. Altı yıllık icraatının anlatıldığg bu belgede I.Hattu_ili, Hahha kenti üzerine yaptığı seferi konu alan satırlarda, kendisinden önce Mala nehrini sadece Sargon'un geçtiğini ve Hahha'nın askerleriyle savaştığını anlatır ${ }^{51}$. Herhalde I.Hattu_ili bu örneği vererek kendi yaptığ işin önemini vurgulamak istemişti.

Wiesbaden 1978, s.322-323. Bu şehrin adı Eski Asur kaynaklarında da Buru_hattum olarak geçer: Bak. K.Nashef, Die Orts-und Gewassernamen der altassyrischen Zeit (RGTC IV), Wiesbaden 19991, s.29-31. Orta Anadolu'da, genellikle Tuz Gölü'nün güneyinde olması gerektiği öne sürülen Puru_handa/Buru_hattum, Acemhöyük'te lokalize edilmek istenmektedir.

Güterbock, $M D O G 101$, s.14 vd.

5n C.Günbatt, "Kültepe'den Akadlı Sargon'a Ait Bir Tablet," Archivum Anatolicum 3 (1997) s.131-155.

si KBo X 2 29-42. Bu konuda bak. H.G.Güterbock, "Sargon of Akkad Mentioned by Hattusili I of Hatti," JCS 18(1964), s.1-6. Ayrıca, adı geçen coğrafya adlarından Mala'nın Fırat'ın Purattu'dan başka bir adı ( del Monte-Tischler, a.g.e., s.537) veya Frrat'in Toroslar'ın kuzeyinde Malatya bölgesindeki kollarından birinin adı (O.R.Gurney, "H.G.Güterbock und H.Otten, Keilschrifttexte aus Boghazköi X." JCS 16 [1962], s.27) olabileceği ileri sürülür. Fırat'ın batısında bir yerde olması gereken Hahha şehrine ilişkin bibliyografya için bak. Del Monte-Tischler. a.g.e., s.61-62. 
Yukarıda içeriğinin özetini verdiğimiz _ar tamhari metninde konumuz açısından üzerinde durulması gereken hususlardan biri, söz konusu dönemde, yani Akkadlı Sargon zamanında, Anadolu'da tüccarlığı meslek edinen kişilerin var olduğu, bunların yerli tüccarlar olabilecekleri gibi, belki de Mezopotamyalı tüccarlar olduklarıdır. Herhalde bunlar a ğırlıkla Anadolu ile Mezopotamya arasinda ticaret yapiyorlard ${ }^{52}$. Sargon'a sikayetlerini ileten tüccarların bu şikayetlerine konu olan Anadolulu bir yerli kraldır. Bu yerli kralın, yani Nur-daggal'ın kendi askerleri olduğunu; Sargon'un yaptı̆̆ 1 sefer sonucunda, Nur-daggal'ın kentinin kapısını yıkarak, duvarlarını delerek ele geçirdiğini; buna göre, bu Anadolu kentinin etrafında sur bulunduğunu ögreniyoruz ${ }^{53}$. Sargon'un kentte büyük y1k1m yapmadan, kolayca ele geçirdiği ve kral Nur-daggal'in hemen teslim oldugu anlaşılmaktadır ${ }_{55}^{4}$. Nurdaggal'ın Hititçe nüshada açıkça görülen kral unvanını taşıyor olmas ${ }^{55}$, onun kentine ilişkin yukarıda belirttiğimiz metinde yer alan ifadeler, burada bir kent devleti ve kent devleti kralı ile karşı karşıya olduğumuzu ortaya koymaktadır. Temsilcilerinin Sargon'un huzuruna kadar çıtı̆̆ğ tüccarlar eğer Anadolulu iseler, bunların o zamanın güçlü devleti Akkad'in kralından yardım istemeye gidecek kadar organize olduklarını; Mezopotamyalı olsalar bile, yine de Anadolu'da organize bir ticaret geleneğinin daha bu zamanlarda yerleşmiş olduğunu göstermektedir.

Akkad Krallı̆̆g'nın tahtında Sargon'dan sonraki üçüncü kral olarak, aynı zamanda onun torunu olan Naram-Sin'i görmekteyiz. Mezopotamya'da ve Anadolu'da ele geçmiş olan ve Naram-Sin'in mücadelelerini konu alan metinlerden $^{56}$, bu kraldan yüzylllar sonrasına ait olmak üzere Boğazköy arşivinde ele geçmiş olan nüshada ${ }^{57}$, Enlil mabedini inşa ettirdikten sonra ona karşı isyan eden kentler krallarının adlarıyla birlikte sayılmaktadır ${ }^{88}$. Bu kentler arasında daha sonraki dönemlere ait bir çok yazılı belge vasıtasıyla Anadolu'da olduklarını bildiklerimiz vardır. Hatti kralı Pamba, Kani kralı Zipani, Amurru kralı Huwaruwa, Sedir Dağları kralı I_qippu, Kur_aura kralı Ti_binki adı okunabilenler arasında bizim açımızdan önem taşıyanlardır. Bunlardan Amurru Suriye'de iken ${ }^{59}$, Sedir Dağları ile

${ }^{52}$ Burada hemen akla M.Ö. 2. binyıl başlarında Anadolu ve Mezopotamya arasındaki Asurlu tüccarlarca yürütülen çok organize ticaret gelmektedir. Asur Ticaret Kolonileri Çăğ'ndaki organize ticari faaliyetlerin ilk ortaya çıkışı Sargon zamanıyla ilgili olabilir. Bak. Günbatt1, a.g.e., s.148.

${ }^{53}$ Tell el Amarna nüshasında ilgili satırlar şöyledir:

ay. 3 "Nur-daggal, ağzını açar ve askerlerine konuşur..."

ay. 7-9 “... Nur-daggal henüz ağzındaki sözü bitirmemişti, o zaman Sargon onun şehrini düşürdü, Prenslerin Kapısını genişletti, iki $i k \hat{u}$ genişliğinde. Onu yıktı, onun duvarının en yüksek kısmında bir gedik açtı, onun sarhoş adamlarının hepsini vurdu..." Bak. Westenholz, Legends of the Kings of Akkade, s.109-113.

${ }_{54}^{54}$ Nitekim I.Hattu_ili'nin Yıllıkları'nda da Sargon'un Hahha'yı "yakıp yıkmadığı ve dumanımı göğe savurmadı̆ için, özellikie vurguladığı bu husus, _ar tamhari'deki Nur-daggal'ın kentine karşı olan tavırla uyuşur.

${ }_{55}^{5} K B o$ XXII 621

${ }_{57}^{56}$ Westenholz, a.g.e., s. $246 \mathrm{vd}$

${ }^{57} \mathrm{KBO}$ III 13 (2BoTÜ 3).

${ }^{58}$ Bak.Güterbock, ZA 44, s.67 vd.; J.G.Westenholz, "Relations Between Mesopotamia and Anatolia in the Age of the Sargonic Kings," XXXIV.Uluslararast Assiriyoloji Kongresi (6-10. VII. 1987 Istanbul), Ankara 1998, s.14 vd

\$9 Amurru'nun Hititçe çivi yazılı metinlerde geçtiğ̣i yer için bak: Ertem, a.g.e.. s.9; del Monte-Tischler, a.g.e., s.14-15. Eski Asurca metinlerdeki için bak: Nashef, a.g.c., s.10-11. 
kastedilen de Amanoslar'dır ${ }^{60}$. Diğger üçü, Hatti, Kani_ve Kur_aura ${ }^{61}$ Anadolu'da yer alır. Akkadlı Naram-Sin'i konu alan söz konusu metinde kralları ile birlikte adları okunabilen diğer şehirlerle ilişkin bu belge dişında bilgi sahibi olamıyoruz. Onlar da herhalde Anadolu'da ve Kuzey Suriye'de olmalıydılar. Naram-Sin'in, adları sayılan toplam 17 kralın olussturduğu ortak bir güce karşı savaştığı ve bunları yendiği anlatılmaktadır. Konumuz açısından dikkat çekici olan husus, Anadolu'da olduğunu kesinlikle bỉldiğimiz kralları ile birlikte sayılan üç şehirden, bunlar ve diğerlerinin bir araya gelerek ortak düşmanlarına karşı mücadele etmiş olmalarından bahsedilmesidir. Anadolu'nun İlk Tunç Çağı'nın son evresine rastlayan bu dönemdeki siyasal yapısına ilişkin olmak üzere, genellikle ortak tehlike karşısında askeri güçlerini bir araya getirebilen kent devletlerinin varlığı yolundaki yorumlar, değindiğimiz kayıtlara dayalı olarak yapılmaktadır.

Başka yazıllı ${ }^{62}$ ve arkeolojik ${ }^{63}$ kanıtlarla da Anadolu'nun protohistorik çağındaki yine Naram-Sin zamanına dair olarak bu topraklara Akkadlar'ın ilgisi gösterilebilmektedir.

Bunların dışında, M.Ö. 24. yüzyıl öncesine ait olmak üzere yine Anadolu'nun siyasal yapısına ilişkin, Anadolu dışında yazının kullanılmış olduğu bir yerden, Ebla arşivi belgelerinden fikir sahibi olmaktayız. Buna göre, söz konusu dönemde Harran, yerel bir sülaleye mensup Zugalum adında bir kraliçe tarafından yönetilmektedir ${ }^{64}$.

Henüz yazının kullanılmadığı Anadolu'nun İlk Tunç Çă̆ı'nın son evresinde, bu toprakların siyasal açıdan nasıl bir görünüm sunduğunu belirlemek için yukarıda da izlenen planın gösterdiği gibi, daha çok kazıların ortaya koyḑuğu sonuçlar bize yardımcı olmaktadır. Çeşitli merkezlerde yapilan arkeolojik kazılarla elde edilen verilere dayanarak yapılmış bu konudaki yorumlar ve yine bu açıdan bizim üzerinde durduğumuz hususların, Anadolu'nun dışında kurulup gelişen ve buraya da ilgi gösteren Akkad uygarlığına ilişkin, ancak nüshaları çok daha sonraki çağlarda kaleme

${ }^{60}$ Bak. del Monte-Tischler, a.g.e., s.143.

${ }_{11}$ Burada geçen Kur_aura'nın, sonraki dönemlerdeki Garsaura(Aksaray) olduğu kabul edilmektedir. Bibliyografya için bak.: Ertem, a.g.e., s.80; del Monte-Tischler,a.g.e., s.227.

${ }^{62}$ CT XIII 44 II 4: H.G.Güterbock, "Die Historischen Tradition und ihre literarische Gestaltung bei Babyloniern und Hethitern bis 1200," ZA 42(1934), s.70,72: Sultantepe tabletleriyle tamamlanmış olarak bak. O.R.Gurney, "The Sultantepe Tablets," An.St. 5(1955), S.100-101. Burada Puru_handa(Buru_handa)'ya sefer yapıldığı ve şehrin tüm bölgesinin talan edildiği yazılıdır. Ancak bu seferi yapan bizzat Naram-Sin değildir.

Ur kazılarında Naram-Sin'in Subartu'ya ve yüksek memleketlere, yani Anadolu'ya yaptığ pl.56 No:275.

${ }^{63}$ Naram-Sin'e ait Diyarbakır yakınında Pir Hüseyin köyünde bulunmuş olan bir stel vardır: E.Unger ve J.P.Naab, Pir Hiiseyin'de Naram-Sin Stelinin Kesfi, İstanbul 1934'de yayınlanmıştır.

Güney Irak'ta Hai bölgesinde bulunan Naram-Sin zamanına verilen bir steldeki tasvirde yer alan bazı unsurlann Anadolu ile ilişkiye işaret ettiği üzerinde durulur: M.Mellink, "An Akkadian Illustration of a Campaign in Cilicia," Anatolia 7(1963), s.101 vd.

Kuzey Suriye'deki Tell Brak'ta yapılan kazılarda Naram-Sin tarafından inşa ettirilmiş büyük bir saray keşfedilmiştir (M.E.L.Mallowan, Twenty-five Yeras of Mesopotamian Discovery, London 1956, s.32-34). Naram-Sin, Anadolu'ya olan seferlerinde burasını üs olarak kullạnmış olmalıydı.

${ }^{64}$ A.Özfirat, Eskiçăg'da Harran, İstanbul 1994, s.35. 
alınmış olarak Anadolu'da da ele geçen kimi belgelerdeki kayıtlara dayalı olarak yapılan yorumlarla uyumlu olduğu ortaya çıkmaktadır. Bunlar birlikte değerlendirildiğinde, üzerinde durduğumuz arkeolojik ve yazılı belge gruplarıyla ulaşılabilen sonuçlar daha güçlü olarak kabul edilebilmektedir. Burada bir kez daha vurgulayacak olursak, İlk Tunç Çağı'nın son evresindeki Anadolu'nun genel siyasal görünümü, belli bir gücü elinde tutan ve çevresindeki daha küçük yerleşim birimlerini ve doğal ya da siyasal sınırlarla belirlenmiş bölgesini kontrol edebilen, saray ve bunun yani sıra başka amaçlarla belki kamu binaları olarak kullanılmış büyük ölçekli mimari yapılara sahip, etrafı surla çevrilmiş kentlerin, kent devletlerinin varlığıyla belirlenmektedir. Belgelerden anlaşıldığına göre, Anadolu'ya gelen Mezopotamyalı krallar, başlarında bir kralı ve ordusu bulunan kentlerle karşılaşmış ve mücadele etmişlerdir. Zira Troia'nın bu evreye tarihlenen tabakasında ve Alacahöyük'te mezarlarda ele geçen buluntular gibi örnekler anımsanacak olursa, bunlar krallara yaraşır zenginliktedir. Büyük zenginlikleri ellerinde toplamış olan kişilerin kentlerin başına geçerek egemenliklerini kentin etrafindaki topraklarda da kabul ettirmeleriyle, kent devletleri olarak tanımladığımız siyasal birimlerin ortaya çıktığı ileri sürülebilir. Kentlerin etrafının surla çevrili olmasının tüm Anadolu'yu kapsayan merkezi bir otoritenin olmamasiyla ilgi kurulabilecek bir olgu olduğu; Naram-Sin seferi örneğindeki gibi ortak tehlike karşısında bir araya gelebilecekleri de görülen söz konusu devletçikler arasında sürekli mücadelelerin bulunduğu da kabul edilmelidir. Ilk Tunç Çağı'nın son evresindeki bu genel siyasal görünümün, artık yazının Anadolu'da da kullanıldığı daha sonraki Asur Ticaret Kolonileri Çağı'nda da geçerli olduğunun, yazılı belgeler aracılığıyla izlenebilmesi ${ }^{65}$ gibi; M.Ö. 2 . binyıl Anadolu'sunda geniş çaplı birliği sağlayan Hitit krallığının, önceki dönemlerin bu siyasal yapısından gelişmiş olduğunun ${ }^{66}$ söylenebilmesi de bu krallığıı kuruluş aşamaları göz önüne alındığında mümkündür.

${ }^{65} \mathrm{Bu}$ dönem Anadolu'sunun siyasal yapısına ilişkin bize bilgiler sunan en dikkate değer tablet, Kültepe'de gün ışı ğına çıkarılmış olan iki yerli Anadolu krallığınin ilişkisi hakkında bilgiler veren bir mektubu içermektedir. Eski Asur dili ve yazısının yerli krallar tarafından da kullanildığını kanıtlayan bu mektup, Mama kralı Anum-Hirbi'den Kani_ kralı War_ama'ya yollanmıştır ( Bak. K. Balkan, Mama Kralt Anum-Hirbi'nin Kani_Kral War_ama'ya Gönderdiği Mektup, Ankara 1957, Anadolu'nun o zamanki siyasal yapısına ilișkin yorum, s. 32-34'tedir). Bu mektuptan söz konusu dönemde Anadolu'da siyasal görünüme ilişkin çıkan sonuç, başında bir kralın bulunduğu, belli bir bölgeyi kontrol eden devletçikler ve yine bunlara bağlı daha alt statüde bir kralın başında bulunduğu kentlerdir. Küçük kralın idaresindeki kent doğrudan bağlı olduğu devletçiğin kontrolündeydi.

Yine bu dönem Anadolu'sunun siyasal yapısına dair yazılı belgelerde saptanabilen bazı küçük kayıtlar için bak. S.Çeçen, "Kültepe Belgelerine Göre Anadolu Şehir Devletlerinde Ayaklanma," Archivum Anatolicum 5(2002), s.65 vd. s.33.

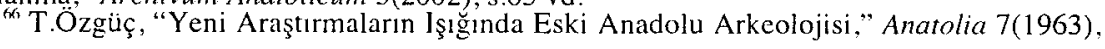




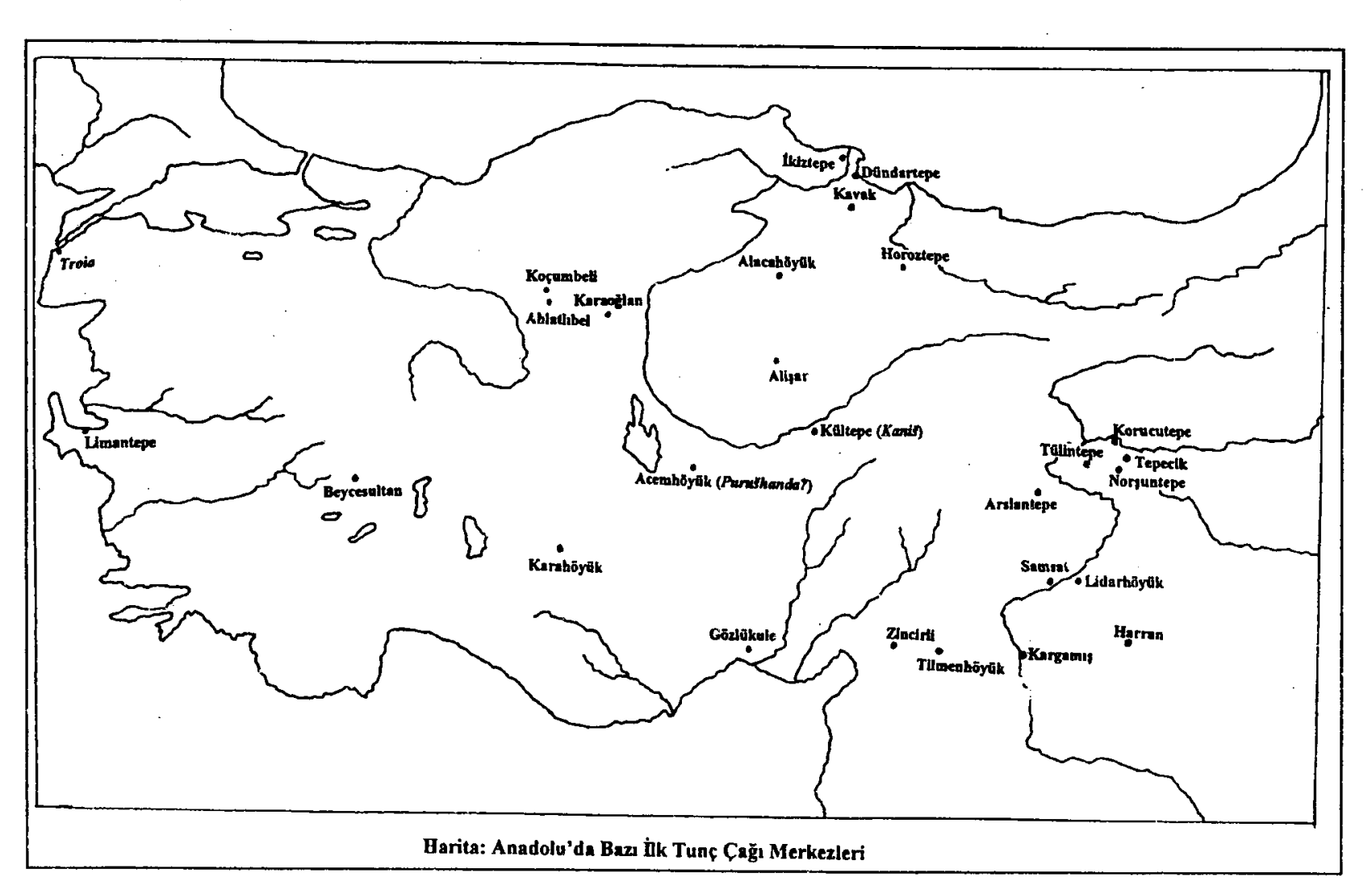




\section{Bibliyografya}

Albright,W.F., "The Epic of the King of Battle: Sargon of Akkad in Cappadocia," JSOR 7 (1923), s.1-20

Alkım,U.B., "Dördüncü Dönem Tilmen Höyük Kazısı (1962)," TAD I2 (1962),s.5-7

Alkım,U.B., "İslahiye Bölgesi Araştırmaları ve Tilmen Höyük Kazısı," TAD 13 (1964),s.5-17

Alkım,U.B. Anatolia I, Geneva 1968

Alkım,U.B.-Alkım,H.-Bilgi,Ö., Ikiztepe I, Ankara 1988

Alp,S., “Karahöyük Kazısı,” Belleten 31, s.456-457

Alp,S., "Karahöyük Kazısı," Belleten 37, s.434-435

Arık,R.O., "Karaoğlan Höyüğüu Bakır Çă̆ı Mimarlığındaki Özellikler," III.Türk Tarih Kongresi 1943,Ankara 1948, s.47-59

Balkan,K., Mama Kralı Anum-Hirbi'nin Kaniş Kralı Warşama'ya Gönderdiği Mektup, Ankara 1957

Blegen,C.W., Troy $I, 1,1950$

Burney,C.A., "Eastern Anatolia in the Chalcolithic and Early Bronze Age," An.St. $8(1958)$, s.157-209

Çeçen,S., "Kültepe Belgelerine Göre Anadolu Şehir Devletlerinde Ayaklanma," Archivum Anatolicum 5(2002), s.65 vd.

Ertem,H., Boğazköy Metinlerinde Geçen Coğrafya Adları Dizini, Ankara 1973

Esin,U., “Tepecik Kazısı, 1970," Keban Projesi 1970 Çalışmalant, Ankara 1972, s.147 vd.

Esin,U., "Tepecik Kazısı, 1974," Keban Projesi 1974-75 Çalışmaları, Ankara 1982, s.71 vd.

Goldmann,H., Excavations at Gözlü Kule, Tarsus II, New Jersey 1956

Gurney,O.R., “The Sultantepe Tablets,” An.St. 5(1955), 93-113

Gurney,O.R., "H.G.Güterbock und H.Otten, Keilschrifttexte aus Boghazköi X," JCS $16(1962)$, s.27

Günbattı,C., "Kültepe'den Akadlı Sargon'a Ait Bir Tablet," Archivum Anatolicum 3 (1997), s.131-155.

Guiterbock,H.G., "Die Historischen Tradition und ihre literarische Gestaltung bei Babyloniern und Hethitern bis 1200," ZA 42(1934),s.1-91

Güterbock,H.G., "Die Tradition und ihre literarische Gestaltung bei Babyloniern und Hethitern bis 1200, Zweiter Teil:Hethiter," ZA 44 (1938),s.45-149 
Güterbock,H.G., "Sargon of Akkad Mentioned by Hattusili I of Hatti," JCS 18(1964), s.1-6

Güterbock,H.G., "Ein neues Bruchstück der Sargon-Erzahlung 'König de Schlacht'," MDOG 101(1969), s.14-26

Hamit Zübeyr, "Ahlatlıbel Hafriyatı," Türk Tarih, Arkeologya ve Etnografya Dergisi 2(1934), s.3-100

Hauptmann,H., "Norşuntepe Kazısı, 1969," Keban Projesi 1969 Çalışmalarl, Ankara 1971 ,s.71 vd.

Hauptmann,H., "Norşuntepe Kazıları, 1971," Keban Projesi 1971 Çalışmaları, Ankara 1974, s.72 vd.

Hauptmann,H., "Norşuntepe Kazıları, 1973," Keban Projesi 1973 Çalışmaları, Ankara 1979, s.43 vd.

Hauptmann,H., "Kalkolitik Çăgdan İlk Tunç Çă̆ının Bitimine Kadar Norşuntepe'de Yerleşmenin Gelişimi," VIII.Türk Tarih Kongresi I.cilt,Ankara 1979, s.55-63

Kansu,Ş.A., Türk Tarih Kurumu Tarafindan Yapılan Etiyokuşu Hafriyatı Raporu (1937), Ankara 1940 Koşay,H.-Akok,M., “Amasya Mahmatlar Köyü Definesi," Belleten 14(1950),s.481-

Koşay,H.Z., "Pulur(Sakyol) Kazısı 1969," Keban Projesi 1969 Çalışmaları, Ankara 1971, s.99 vd.

Koşay,H.Z.-Akok,M., Alacahöyük Kažlst, 1963-67 Çalışmalar ve Keşiflere Ait Ilk Rapor, Ankara 1973,

Lloyd,S., "The Early Settlement of Anatolia," The Dawn of Civilization, London $1961, \mathrm{~s} .161-194$

Lloyd,S.-Mellart,J., Beycesultan I, London 1962

Lloyd,S., Early Highland Peoples of Anatolia, London 1967

Loon,M.N.van, Korucutepe II, New York 1978

Mallowan,M.E.L., Twenty-five Yeras of Mesopotamian Discovery, London 1956

Mellaart,J., "The End of the Early Bronze Age in Anatolia and the Aegean," AJA 62 (1958), s.9-33

Mellaart,J., The Chalcolithic and Early Bronze Ages in the Near East and Anatolia, Beirut, 1966

Mellaart,J., "Anatolia, c.2300-1750," CAH I/2, Cambridge 1971, s.681-706

Mellink,M., "An Akkadian Illustration of a Campaign in Cilicia," Anatolia 7(I963),s.101-115 
Mellink,M., "The Early Bronze Age in West Anatolia," The End of the Early Bronze Age in the Aegean (ed. Gerald Cadogan), Leiden 1986, s.139-152

Monte,G.F.del-Tischler,J., Die Orts-und Gewassernamen der hethitischen Texte (RGTC VI), Wiesbaden 1978

Nashef,K., Die Orts-und Gewassernamen der altassyrischen Zeit (RGTC IV), Wiesbaden 1991

Özguiç,T.-Akok,M., Horoztepe, Eski Tunç Devri Mezarlı̆̆ı ve Iskan Yeri, Ankara 1958

Özgüç, T., "Yeni Araştırmalar Işı̆̆̆ında Eski Anadolu Arkeolojisi," Anatolia 7 (1963), s.23-42

Özfırat, A., Eskiçă̆'da Harran, İstanbul 1994

Sevin, V., Anadolu Arkeolojisi, İstanbul 1997

Schroeder,O., "Die beiden neueu Tontafel," MDOG 55 (1914), s.39-45

Smith,S., Ur Excavations Texts I ,pl.56 No:275.

Tezcan,B., 1964 Koçumbeli Kazısı, Ankara 1966

Unger,E- Naab,J.P., Pir Hüseyin'de Naram-Sin Stelinin Keş̧i, İstanbul 1934

Westenholz,J.G., "Relations Between Mesopotamia and Anatolia in the Age of the Sargonic Kings," XXXIV.Uluslararasi Assiriyoloji Kongresi (6-10. VII. 1987 Ístanbul), Ankara 1998, s.5-22.

Westenholz, J.G., Legends of the Kings of Akkade, The Texts, Indiana 1997

Weidner,E., Der Zug Sargons von Akkad nach Kleinasien, BoSt VI,1922

Yakar,J.,The Later Prehistory of Anatolia,The Late Chalcolithic and Early Bronze Age, 1985, I, II

Yakar J., "Regional and Local Schools of Metalwork in Early Bronze Age Anatolia," An.St. 35(1985), s25-38 